Research Article

\title{
Retrospective Assessment of the Clinical Pharmacist Sheets among a Few Iraqi General Hospitals
}

\author{
Karrar Mohammed Abbas', Manal Khalid Abdulridha² \\ ${ }^{1}$ Ministry of Health, Thiqar Health Directorate, Iraq. \\ 2Department of Clinical Pharmacy, College of Pharmacy, Mustansiriyah University, Iraq. \\ DOI: https://doi.org/10.24321/0019.5138.202175
}

\section{I $\quad \mathbf{N} \quad \mathbf{F} \quad \mathbf{O}$}

\section{Corresponding Author:}

Manal Khalid Abdulridha, Department of Clinical Pharmacy, College of Pharmacy, Mustansiriyah University, Iraq.

E-mail Id:

pharm.mrdha@uomustansiriyah.edu.iq Orcid Id:

https://orcid.org/0000-0002-5059-7963

How to cite this article:

Abbas KM, Abdulridha MK. Retrospective Assessment of the Clinical Pharmacist Sheets among a Few Iraqi General Hospitals. J Commun Dis. 2021;53(4):61-69.

Date of Submission: 2021-09-21

Date of Acceptance: 2021-10-16

\section{$\begin{array}{llllllll}\mathbf{A} & \mathbf{B} & \mathbf{S} & \mathbf{T} & \mathbf{R} & \mathbf{A} & \mathbf{C} & \mathbf{T}\end{array}$}

Background: Clinical pharmacist sheet is an essential part of the medical record; it highlights the pharmacist's role during hospitalisation through the concept of pharmaceutical care and specific pharmacist collaboration with a patient and other health care teams.

Objective: To assess the documentation completeness level of the clinical pharmacist sheet, pharmacist intervention, type and prevalence of Drug-Related Problems.

Methodology: A retrospective observational study that included revised 3900 clinical pharmacist sheets from Baghdad and Thiqar Hospitals for 2018,2019 , and 2020. The forms from four departments of the hospitals (internal medicine, surgery, paediatrics, gynaecology and obstetrics). In addition, assessment completeness of the pharmacist documentation level in the clinical pharmacist sheets, and Pharmacist interventions.

Results: The overall documentation completeness level in the clinical pharmacist sheets was generally poor (less than $50 \%$ of the sheet items were filled in). The best documentation level was presented in the surgery ward (52.34\%). A total of 3900 clinical pharmacist sheets were analysed within multi-ward hospitals that revealed variable percentages of DRPs $(10 \%, 8.55 \%, 12.44 \%$, and $7.42 \%)$ in internal medicine, surgery, gynaecology and obstetrics, and paediatric respectively. Findings also revealed a significant decline in pharmacist interventions over the last three years.

Conclusion: There was poorn documentation completeness level and pharmacist interventions over the last 3 years among clinical pharmacist sheets. Drug selection, dosing, and substituting unavailable drugs with an alternative were the commonest causes of DRPs.

Keywords: Drug-Related Problems (DRPs), Clinical Pharmacist, Pharmacist Intervention 


\section{Introduction}

Clinical pharmacists are shouldering numerous responsibilities depending upon the available resources in the health care system. ${ }^{1}$ These responsibilities and duties vary from prescription review up to prescribing drugs. Australian's Society of Hospital Pharmacy divided them into Patient Medication History, Profile Patient Review, Adverse Drug Reaction Management, Therapeutic Drug Monitoring (TDM), Drug Information Management, and Patient Counselling. ${ }^{2}$ Clinical pharmacist sheet is an essential part of the medical record; it highlights the pharmacist's role during inpatient care through the concept of pharmaceutical care and specific pharmacist collaboration with a patient and other health care teams for good therapeutic outcomes. ${ }^{1}$

Clinical pharmacists participate with other multidisciplinary teams to optimise patients' pharmacotherapy, minimise medication errors, and detect and manage drug-related problems during medical rounds. ${ }^{3}$ Activities involving patient care within the multi-ward in hospital settings result in effective and safe medication use. ${ }^{4}$

Pharmaceutical care is an essential new concept that rapidly developed after establishing professional pharmacist activities, involving medication preparation and dispensing with the necessity to integrate between clinical pharmacist and individual patients for satisfying desired outcomes. ${ }^{2,5}$ Good pharmaceutical care improved patients' quality of life and minimised DRPs. ${ }^{6}$ Preventable adverse events each year across a wide range of drug classes can be diminished by clinical pharmacist review of medications chart, and can thus improve patient outcome., ${ }^{7,8}$ The patient should be supported with the updated knowledge of their disease condition, medication, and appropriate lifestyle modifications required to understand their condition and thereby improve their quality of life, and prevent or minimise drug-related problems. ${ }^{9}$ Therefore, there is an urgent need to evaluate and document the role of clinical pharmacist services in the health care team.

Pharmaceutical care is a form of pharmacy practice in which pharmacists respond to the needs of the patients and offer the best services and most evidence based treatment possible. ${ }^{10}$ Medication therapy review and pharmacist interventions are provided by the pharmacist based on several guidelines. ${ }^{11}$ Continuing professional development is described as pharmacists' responsibility for periodic maintenance, development, and broadening knowledge, skills, and attitudes to ensure continuedcompetence as professionals throughout their careers. Their efficient collaboration with the health team is crucial as well, as a result; the benefits of a pharmacist's intervention and good documentation potentially improve economic and health-related quality of life, and can provide integrated drug management to patients and caregivers. ${ }^{12,13}$

\section{Methodology}

This is a retrospective observational study on revised clinical pharmacist sheets from Baghdad and Thiqar Hospitals for 2018, 2019, and 2020 which were included from four departments of the hospitals (internal medicine, surgery, paediatrics, gynaecology and obstetrics). Data regarding assessment completeness of the pharmacist documentation level in the clinical pharmacist sheets, assessment of clinical pharmacist interventions according to the Pharmaceutical Care Network Europe (PCNE) classification system for drug-related problems, and assessing any changes in pharmacist intervention each year among different wards, were collected and the sum of drug therapy problems reported in the documented clinical pharmacist sheet was assessed retrospectively. Any inpatient records lacking medication-consult sheets, patient files without admission or discharge date, or patients leaving before 48 hours of admission were excluded from the study. The total number of clinical pharmacist sheets to be revised retrospectively were about 3900 . Also, the sum of drug therapy problems reported in the documented clinical pharmacist sheet, revised annually, was collected to assess any changes in pharmacist interventions each year among different wards.

\section{Results}

\section{Documentation Completeness Level of Clinical Pharmacist Sheets among Multi-ward Hospitals}

Figure 1 reveals the documentation completeness level of multi-ward hospitals. In the department of internal medicine in the current study, the figures decreased from $43 \%$ to $33 \%$ (from 2018 to 2020) and in general surgery, the figures were $64 \%$ and $67 \%$ for 2018 and 2019 respectively, and declined after that. The completeness level in gynaecological and obstetric wards was $43 \%$ in $2018,35 \%$ in 2019 , and $29 \%$ in 2020. Paediatric ward sheets demonstrated completeness levels of $46.5 \%$ and $44 \%$ for 2018 and 2019 , respectivel as good documentation and declined after that.

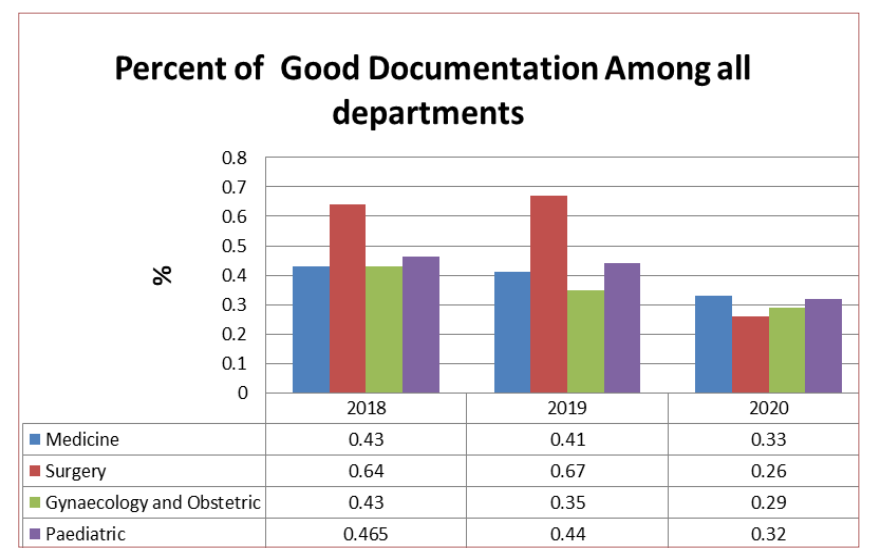

Figure I.Percentage of Good Documentation for Three Years among Various Departments 
Drug-related Problems according to PCNE Category among Hospital Wards

The various drug-related problems identified from clinical pharmacist sheets of six Iraqi hospitals over the past 3 years $(2018,2019$, and 2020) from both governorates (Baghdad and Thiqar) were as follows:

The DRPs identified from internal medicine ward sheets according to PCNE showed that unavailability of drugs represented a major problem (35.55\%), while, treatment monitoring deficits represented $20.0 \%$ of DRP. Dosingrelated problems represented $18.87 \%$, and drug selection problems revealed $16.65 \%$ of DRPs as shown in Table 1. Also, the DRPs identified as per the general surgery ward sheets showed that unavailability of drugs represented a major problem (32.46\%), while, dosing-related problems represented $24.65 \%$ and drug selection problems constituted $12.96 \%$ of DRPs as shown in Table 2. The DRPs identified from gynaecological and obstetric ward sheets showed that unavailability of drugs constituted a major problem (32.14\%) while drug selection problems constituted 22.3\%, and dosing related problems represented $11.59 \%$ of DRPs as shown in Table 3.

Table I.Causes of Drug-Related Problems in Internal Medicine Ward

\begin{tabular}{|c|c|c|c|}
\hline \multirow{2}{*}{ Causes of DRPs } & \multirow{2}{*}{ PCNE } & \multicolumn{2}{|c|}{ DRPs } \\
\cline { 3 - 4 } & Category & $\mathbf{n}$ & $\mathbf{( \% )}$ \\
\hline ADR & P2.1 & 2 & 2.22 \\
\hline Monitoring & C9.1 & 18 & 20.00 \\
\hline Administration & C6.6 & 1 & 1.11 \\
\hline Drug-food interaction & C7.5 & 0 & 0.0 \\
\hline Drug selection problems & C1 & 15 & 16.65 \\
\hline DDI & C1.4 & 8 & 8.88 \\
\hline Cl & C1.1 & 7 & 7.77 \\
\hline Patient adherence & C7.8 & 1 & 1.11 \\
\hline Dosing related problems & C3 & 17 & 18.87 \\
\hline High dose & C3.2 & 6 & 6.66 \\
\hline Low dose & C3.1 & 8 & 8.88 \\
\hline Dosage regimen too frequent & C3.4 & 3 & 3.33 \\
\hline Dispensing & C5 & 0 & 0.0 \\
\hline Unavailability of drug & C5.1 & 32 & 35.55 \\
\hline Others & C9.2 & 4 & 4.44 \\
\hline Add new drug & & 90 & 100 \\
\hline Total & & & \\
\hline
\end{tabular}

Data has been presented as number ( $n$ ) and percentage (\%).

Finally, the DRPs identified from the 4 general hospitals' 1200 paediatric ward sheets according to the PCNE showed that unavailability of drugs represented the main problem
(26.97\%), along with drug selection problems constituting $22.47 \%$, dosing related problems accounting for $17.98 \%$, and ADR representing $17.98 \%$ of DRPs as shown in Table 4.

Table 2.Causes of Drug-Related Problems in Surgery Ward

\begin{tabular}{|c|c|c|c|}
\hline \multirow{2}{*}{ Causes of DRPs } & \multirow{2}{*}{$\begin{array}{c}\text { PCNE } \\
\text { Category }\end{array}$} & \multicolumn{2}{|c|}{ DRP } \\
\hline & & $\mathbf{n}$ & $\%$ \\
\hline ADR & P2 & 6 & 7.79 \\
\hline Monitoring & C9.1 & 0 & 0 \\
\hline Administration & C6.1 & 1 & 1.29 \\
\hline Drug-food interaction & C7.5 & 0 & 0 \\
\hline Drug selection problems & $\mathrm{C} 1$ & 10 & 12.96 \\
\hline DDls & C1.4 & 5 & 6.49 \\
\hline No indication for a drug & C1.3 & 1 & 1.29 \\
\hline $\begin{array}{c}\text { Inappropriate duplication of } \\
\text { drugs }\end{array}$ & C1.5 & 2 & 2.59 \\
\hline Too many drugs prescribed & C1.7 & 2 & 2.59 \\
\hline Patient adherence & C7.1 & 4 & 5.19 \\
\hline Dosing related problems & C3 & 19 & 24.65 \\
\hline Drug dose too low & C3.1 & 7 & 9.09 \\
\hline Drug dose too high & C3.2 & 5 & 6.49 \\
\hline $\begin{array}{c}\text { Dosage regimen not frequent } \\
\text { enough }\end{array}$ & C3.3 & 3 & 3.89 \\
\hline Dosage regimen too frequent & C3.4 & 3 & 3.89 \\
\hline Wrong dose instructions & C3.5 & 1 & 1.29 \\
\hline Dispensing & C5 & 0 & 0 \\
\hline Unavailability of drug & C5.1 & 25 & 32.46 \\
\hline \multicolumn{4}{|l|}{ Other } \\
\hline Add new drug & C9.2 & 6 & 7.79 \\
\hline $\begin{array}{l}\text { Duration of treatment too } \\
\text { long }\end{array}$ & C4.2 & 1 & 1.29 \\
\hline Cost comparison & C9.2 & 2 & 2.59 \\
\hline Iv incompatible & C9.2 & 3 & 3.89 \\
\hline Total & & 77 & 100 \\
\hline
\end{tabular}

Data has been presented as number ( $n$ ) and percentage (\%).

Table 3.Causes of Drug-Related Problems in Gynaecology and Obstetrics Ward

\begin{tabular}{|c|c|c|c|}
\hline \multirow{2}{*}{ Causes of DRPs } & \multirow{2}{*}{ PCNE } & \multicolumn{2}{|c|}{ DRP } \\
\cline { 3 - 4 } & Category & $\mathbf{n}$ & $\%$ \\
\hline ADR & P2 & 9 & 8.03 \\
\hline Monitoring & C9.1 & 4 & 3.57 \\
\hline Administration & C6 & 10 & 8.92 \\
\hline Wrong dosing interval & C6.1 & 2 & 1.78 \\
\hline
\end{tabular}




\begin{tabular}{|c|c|c|c|}
\hline $\begin{array}{c}\text { Drug administered via a } \\
\text { wrong route }\end{array}$ & $\mathrm{C} 6.6$ & 8 & 7.14 \\
\hline $\begin{array}{c}\text { Drug-food interaction } \\
\text { Drug-selection problems }\end{array}$ & $\mathrm{C} 7.5$ & 0 & 0 \\
\hline Contra-indication & $\mathrm{C} 1.1$ & 25 & 22.3 \\
\hline DDIs & $\mathrm{C} 1.4$ & 6 & 5.35 \\
\hline $\begin{array}{c}\text { Wrong duplication of } \\
\text { therapeutic group }\end{array}$ & $\mathrm{C} 1.5$ & 12 & 10.71 \\
\hline Too many drugs prescribed & $\mathrm{C} 1.7$ & 1 & 0.89 \\
\hline Patient adherence & $\mathrm{C} 7.1$ & 11 & 9.82 \\
\hline Dosing & $\mathrm{C} 3$ & 13 & 11.59 \\
\hline Drug dose too low & $\mathrm{C} 3.1$ & 3 & 2.67 \\
\hline Drug dose too high & $\mathrm{C} 3.2$ & 7 & 6.25 \\
\hline $\begin{array}{c}\text { Dosage regimen too } \\
\text { frequent }\end{array}$ & $\mathrm{C} 3.4$ & 3 & 2.67 \\
\hline Dispensing & $\mathrm{C} 5$ & 0 & 0 \\
\hline Unavailability of drug & $\mathrm{C} 5.1$ & 36 & 32.14 \\
\hline Other & \multicolumn{3}{|l}{} \\
\hline Add new drug & $\mathrm{C} 9.2$ & 4 & 3.57 \\
\hline Total & \multicolumn{1}{|c|}{112} & 100 \\
\hline
\end{tabular}

Data has been presented as number (n) and percentage (\%).

Table 4.Causes of Drug-Related Problems in Paediatric Ward

\begin{tabular}{|c|c|c|c|}
\hline \multirow{2}{*}{ Causes of DRPs } & \multirow{2}{*}{ PCNE } & \multicolumn{2}{|c|}{ DRP } \\
\cline { 3 - 4 } & Category & $\mathbf{n}$ & $\%$ \\
\hline ADR & P2 & 16 & 17.98 \\
\hline Monitoring & C9.1 & 0 & 0 \\
\hline Administration & C6 & 4 & 4.49 \\
\hline Drug over administered & C6.3 & 1 & 1.12 \\
\hline $\begin{array}{c}\text { Inappropriate timing of } \\
\text { administration or dosing } \\
\text { interval }\end{array}$ & C6.1 & 3 & 3.37 \\
\hline Drug-food interaction & C7.5 & 0 & 0 \\
\hline Drug-selection problems & (C1) & 20 & 22.47 \\
\hline Cl & $\mathrm{C} 1.1$ & 4 & 4.49 \\
\hline No indication for drugs & $\mathrm{C} 1.3$ & 1 & 1.12 \\
\hline DDI & $\mathrm{C} 1.4$ & 10 & 11.23 \\
\hline $\begin{array}{c}\text { Inappropriate duplication of } \\
\text { therapeutic group }\end{array}$ & $\mathrm{C} 1.5$ & 4 & 4.49 \\
\hline Too many drugs prescribed & $\mathrm{C} 1.7$ & 1 & 1.12 \\
\hline Patient adherence & $\mathrm{C} 7.1$ & 1 & 1.12 \\
\hline Dosing related problems & $\mathrm{C} 3$ & 16 & 17.98 \\
\hline Drug dose too low & $\mathrm{C} 3.1$ & 9 & 10.11 \\
\hline
\end{tabular}

\begin{tabular}{|c|c|c|c|}
\hline Drug dose too high & $\mathrm{C} 3.2$ & 2 & 2.25 \\
\hline Dosage regimen too frequent & $\mathrm{C} 3.4$ & 2 & 2.25 \\
\hline Wrong dose instructions & $\mathrm{C} 3.5$ & 3 & 3.37 \\
\hline Dispensing & $\mathrm{C} 5$ & 0 & 0 \\
\hline Unavailability of drug & $\mathrm{C} 5.1$ & 24 & 26.97 \\
\hline Other & $\mathrm{C} 4.2$ & 2 & 2.25 \\
\hline $\begin{array}{c}\text { Duration of treatment too long } \\
\text { IV incoAdd new drug } \\
\text { mpatible }\end{array}$ & $\mathrm{C} 9.2$ & 2 & 2.25 \\
\hline Total & $\mathrm{C} 9.2$ & 4 & 4.49 \\
\hline
\end{tabular}

Data has been presented as number ( $n$ ) and percentage (\%).

\section{Changes in Pharmacist Interventions among different Hospitals Wards}

Figure 2 shows the percentage of pharmacist interventions within multi-ward hospitals. The percentage for paediatric ward was $16.33 \%$ in 2018 and declined after that. $13.66 \%$ was the best recorded figure in the surgery ward during 2019.The percentage for gynaecological and obstetric ward did not exceed $9.5 \%$ in 2018. The internal medicine ward reached $12.33 \%$ in 2018 and declined in 2019 and 2020.

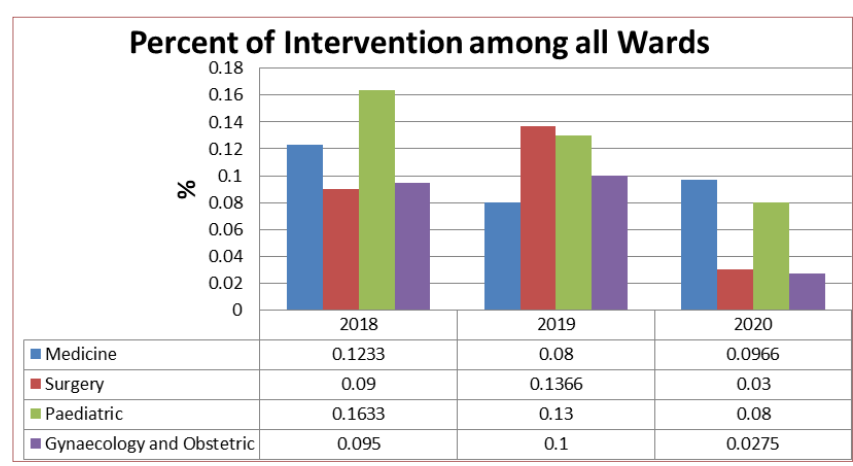

Figure 2 .Percentage of Pharmacist Intervention for Three Years a

\section{Discussion}

Documentation-completeness of Clinical Pharmacist Sheet among Different Wards

The core responsibilities of inpatient pharmacists include reviewing and documenting interventions in the clinical pharmaceutical sheet. ${ }^{14}$ Medical documentation is a comprehensive, reliable, sufficient, timely assists healthcare practitioners in minimising medical errors, and serves as valuable medical-legal evidence. ${ }^{15}$ Complete documentation of medication review and other elements related to the patient's condition is extremely important for admitted patients, and the absence of any critical information may result in unfavourable treatment-related problems. ${ }^{16}$

This study of documentation completeness level of the 
internal medicine in the current study done retrospectively for 3 years by random sampling of 900 clinical pharmacist sheet from 3 hospitals (Baghdad teaching hospital, AlHussien teaching hospital, and Souq-Al-Shiukh general hospital) revealed poor documentation level (39\%). Nevertheless, the completeness level of documentation of clinical pharmacist sheet of the general surgery ward was fairly consistent (52.34\%) as good for 2018, 2019 and 2020. Moreover, the completeness level of randomly sampled clinical pharmaceutical sheets from the gynaecological and obstetric ward (Baghdad teaching hospital, Bint Al-Huda teaching hospital, and Souq-Al-Shiukh general hospital) was $35.7 \%$.

Paediatric ward sheets in the current study (Welfare teaching hospital for paediatric in Baghdad province, Bint-Al-Huda teaching hospital, Mohammed Al-Mosauy and Souq Al-Shiukh general hospital in Thiqar province) demonstrated poor completeness levels (40.8\%). Previous studies conducted in different countries worldwide as in Rwanda reported an increase in the completeness of medical records of the maternity unit over one year $(25 \%$ to $67 \%) .{ }^{17}$ Another study conducted in Ethiopia reported a gap in medical record completeness before and after one year of a quality intervention programme, after which the completeness of medical records improved from $14 \%$ to $84 \% .^{18}$ Moreover, the documentation of the pharmacological history of admitted patients was found to be frequently inadequate in a study involving 304 admitted patients from two hospitals in the Netherlands, with $61 \%$ of the patients' records being incomplete. ${ }^{15}$ Careful documentation in a paediatric ward contributes to better patient assessments more accurate and timely diagnosis along with proper treatment, and allows other health care providers to follow treatment outcomes. ${ }^{19}$

The poor documentation completeness in the current study probably reflected some lack in pharmacist practice to properly document pharmaceutical sheets on one hand, and on the other hand, they may have been caused due to defects in applying quality intervention programmes particularly those concerning general internal medicine and multiple prescriptions. A recent pilot study (2020) among different wards in Iraqi hospitals reported incomplete documenting of the majority of clinical pharmaceutical sheets for the inpatient, particularly in the surgery ward..$^{20}$

\section{Drug Related Problems in Clinical Pharmacist Sheets (CPS) over Three Years}

Data collected from Baghdad teaching hospital, Al-Hussien teaching hospital and Souq-Al-Shiukh teaching hospital distributed in Baghdad and Thiqar provinces after reviewing 900 CPS for 3 years revealed several types of DRPs detected in the internal medicine ward in the current.With reference to the PCNE classification system, items of DRPs in the clinical pharmaceutical sheet included in the patient's file were matched with those in other studies. ${ }^{21}$ This scope highlighted the importance of medication review and the presence of clinical pharmacists during tour as a full member of the patient care team in internal medicine ward. It showed that they were probably associated with a substantially lower rate of adverse drug events caused by prescribing errors.

The influence of poly-pharmacy was described in many previous studies. ${ }^{22,23}$ Lenssen et al. identified poly-pharmacy as a significant risk factor for DRP growth. ${ }^{24}$ Moreover, overall $10.5 \%$ of medication errors were reported in Northwest England hospitals, ${ }^{25}$ which is close to the current finding. Dosing related problem was also a crucial one (18.87\%) particularly high dose, low dose, and too frequent dosage. Drug selection was another type of DRP in the internal medicine ward (C1, 16.65\%), which caused drug interaction and contraindication. Similar findings were reported previously in 2011in one of the national hospitals where dosage or frequency of medication followed by addition of drugs to therapy represented the most common issue $\left(32.4 \%\right.$ and $19.5 \%$ respectively) ${ }^{26}$ Globally, as per a study conducted at a multi-specialty teaching hospital, the suboptimal dosing was the most common DRP, ${ }^{27}$ Most of the common improper drug selection was related to antibiotics, which is in line with a previous study where anti-infective was the most common class of drug for DRPs. ${ }^{28}$

In the current study, the overall percentage of DRPs was $8.5 \%$ of the total clinical pharmaceutical sheets reviewed, which was less than that of the internal medicine ward probably due to low number of drugs dispensed pre and post-operatively. This percentage could be acceptable compared to a few studies done in developed countries that showed that the values reported in a German orthopaedic and accident surgery ward using the APS-Doc coding and Swiss cardiovascular surgery ward using a simplified PCNE classification system were $2.6 \%{ }^{29}$ And $1.7 \%,{ }^{30}$ respectively. Another DRPs that reported in the Indian tertiary teaching hospital were $47.6 \% .{ }^{31}$ The issue of unavailability of drugs (C5.1, 32.46\%) that represented a major problem and required recommending drug replacement with another alternative, was not very common elsewhere. Dosing related problems $(C 3,24.65 \%)$ (particularly too low and too high dose) besides the improper drug selection leading to DDI mainly $(C 1,12.96 \%)$, represented the major problems in this study. The other category represented less than $10 \%$ of DRPs.

A previous hospital-based prospective observational study (2010) designed to assess the prevalence of DTP among patients hospitalised at the surgical ward stated that too low $(27.6 \%)$ and too high (18.0\%) doses were found to be the most common types of DTPs, ${ }^{32}$ This is in agreement 
with the current finding. Also, in a prospective cohort study (2020) conducted in a Brazilian University Hospital with a total of 12,286 hospitalisation episodes, the DRP detected using Pharmaceutical Care Network Europe 6.2 classification showed that drug use process (18.4\%) and treatment duration (31.0\%) were the main causes of DRP. ${ }^{33}$ A very recent study (2021) conducted among elderly patients from surgical departments classified based on the Pharmaceutical Care Network Europe classification V8.02 reported drug selection (43.1\%) and dose selection $(43.1 \%)$ as the major causes of DRP from a total of 53,231 medication order forms. The results were in line with the current finding except for a higher percentage related to the number of reviewed sheets. ${ }^{34}$

Drug related problems detected from gynaecological and obstetric ward sheets from three Iraqi hospitals (Baghdad teaching hospital, Bint Al-Huda teaching hospital, and Souq Al-Shiukh general hospital) were collected and reviewed. In the current study, the overall percentage of DRPs was $12.44 \%$ of the total clinical pharmaceutical sheets reviewed which was higher than that of the abovementioned wards. The unavailability of drugs, drug selection problems (mainly duplication of therapeutic group, and dosing related problems (C3), all accounted for more than $65 \%$ of cases of DRPs. Also, patient adherence problems (C7.1), administration problems(C6) and ADR problems (P2) represent more than $25 \%$ of medication-related problems. This finding was lower than that reported in a Norwegian study where the need for additional drugs was $46.7 \%$ out of 212 women and was the most frequent. ${ }^{35}$ In an Australian study, the highest number of DRPs(49\%) was identified among a total of 454 women admitted following caesarean delivery. ${ }^{36}$ Recently, in a developing country, among 323 study participants, DRPs mostly in relation to lack of iron supplementation were $70.6 \% .{ }^{37}$ This large variation in type and percentage of DRPs is likely due to the scope of health care systems, population sample size, and disease distribution.

Paediatric patients are the vulnerable population who are susceptible and sensitive to drug related problems due to their underdeveloped physiological conditions and lack of accurate doses and dosage forms. ${ }^{38}$ Four paediatric wards were selected from 4 Iraqi hospitals:Welfare teaching hospital of paediatric, Mohammed Al-Mousaoy for paediatric, Bint Al-Huda teaching hospital,and Souq Al-Shiukh general hospital located in Baghdad and Thiqar provinces. Reviewing 1200 sheets showed 7.42\% DRPs as an average. Unavailability of drugs, drug selection problems, and dosing related problems were the major categories similar to other mentioned wards. Drug dose too low and DDI were the most recorded in paediatric sheets. Notably, ADR was reported in $17.98 \%$, of paediatric cases which was much higher than the other wards. A percentage of $17.3 \%$ was reported in a prospective study in Babylon Hospital for Gynaecology and Children for 3 months. ${ }^{5}$ Also, $13.4 \%$ was reported by Rashed et al. ${ }^{39}$ Others reported (71\%) major drug interaction, moderate drug interaction and minor drug interaction based on its effect on the therapy of patients. ${ }^{40}$

In developed countries, studies reported other types of DRPs like treatment effectiveness, treatment safety, and non-conformity to guidelines identified in the medication charts. ${ }^{41,42}$ along with those related to the choice of drug and drug dosing. ${ }^{43}$ The variation could be attributed to differences in training levels of prescribers, knowledge of health professionals responsible for medication review especially the pharmacist, availability of support systems and inter-professional collaboration, and composition of the health care team in these hospitals. ${ }^{44}$

\section{Changes in Pharmacist Intervention Over Three Years}

In the current study, no change in pharmacist intervention was noticed over the past 3 years (2018, 2019 and 2020), though with a very low level of intervention. Also, the pharmacist intervention was fluctuating in the surgery ward with a significant decline in the last year (2020). Moreover, a significant decline was noticed in the percentage of pharmacist intervention in Gynaecology and Obstetric ward sheets, similarly to the paediatric ward.From these findings, it can be speculated that this decline in the pharmacist intervention among different hospital wards starting from 2019 could be attributed to the outbreak of the COVID-19 pandemic. A reasonable number of studies described the role of the pharmacists during the COVID-19 pandemic as important, while some reported a negligible role. ${ }^{45,46}$ The overall percentage of pharmacist interventions over the 3 years did not exceed (9.6\%) in the current study. In agreement with the current study finding, the computerised physician order in multi-ward from Grenoble University Hospital reported pharmacist interventions equal to $15.7 \%{ }^{47}$; a higher percentage was stated by Falcao et al. ${ }^{48}$ The physician-pharmacist collaborative partnerships and trust worthiness is a key factor to clinically validate and evaluate any pharmacist intervention. ${ }^{49}$

\section{Conclusion}

There was a decline in documentation completeness-level in subsequent years among clinical pharmacist sheets from different hospitals wards.The best level of documentation completeness was noticed in the general surgery wards. The drug selection problem, dosing related problems, and unavailability of drugs specifically indicated, was the predominant categories of DRPs. A significant variation in the pharmacist intervention over the 3 years was noticed in sheets of surgery, gynaecology, and paediatric wards. 


\section{Limitations of the Study}

The collected samples of clinical pharmacist sheets were limited to six hospitals within two provinces retrospectively to 3 years only, and cannot be presumed to be representative of all hospitals. Also, because of physical environment challenges and poor handling of patient files in many hospitals, the current study could not be extended for more than 3 years.

\section{Acknowledgement}

The authors acknowledge all health institutions targeted during research.

\section{Ethical Approval}

It was obtained by health, higher education and scientific research ministries in Iraq.

Funding: Self-funding

\section{Conflict of Interest: None}

\section{References}

1. Nissen L. Current status of pharmacist influences on prescribing of medicines. Am J Heal Pharm. 2009 Mar;66(5 Suppl 3):S29-34. [PubMed] [Google Scholar]

2. Elements P. ASHP Statement on Pharmaceutical Care. Medication therapy and patient care: organization and delivery of services statements. Best Pract. 2020:331-3.

3. Talasaz AH. The potential role of clinical pharmacy services in patients with cardiovascular diseases. J Tehran Univ Hear Cent. 2012 Spring;7(2):41-6. [PubMed] [Google Scholar]

4. Amir M. Clinical pharmacy practice: An activity based definition for pharmacy students of developing countries. Arch Pharm Pract. 2012;3(3):193. [Google Scholar]

5. Chillab RZ, Al-Sabbagh M, Fakhri H. Evaluation of pharmaceutical care application in Iraqi hospital. AJPS. 2009;6(1):18-31.[Google Scholar]

6. Baiz HQ, Aziz TA, Sharif DA. Potential effect of pharmaceutical care to improve outcomes in patients with chronic kidney disease-mineral bone disorder in Sulaimani dialysis centers. Al Mustansiriyah J Pharm Sci. 2020;20(1):82-94.[Google Scholar]

7. Runciman WB, Roughead EE, Semple SJ, Adams RJ. Adverse drug events and medication errors in Australia. Int J Qual Heal Care. 2003 Dec;15 Suppl 1:i49-59. [PubMed] [Google Scholar]

8. Ahmed B, Nanji K, Mujeeb R, Patel MJ. Effects of polypharmacy on adverse drug reactions among geriatric outpatients at a tertiary care hospital in Karachi: a prospective cohort study. PLoS One. 2014 Nov;9(11):e112133. [PubMed] [Google Scholar]

9. Mallesh M, Reddy KP, Reddy PVN. Evaluation of the clinical pharmacist role in a health care team; a comparative approach. Indian J Pharm Pract. 2016;9(4):236-46.[Google Scholar]

10. World Health Organization. Joint FIP/WHO guidelines on good pharmacy practice: standards for quality of pharmacy services. WHO Technical Report Series.2011;961:8-14.

11. Jokanovic N, Tan ECK, van den Bosch D, Kirkpatrick CM, Dooley MJ, Bell JS. Clinical medication review in Australia:a systematic review. Res Soc Adm Pharm. 2016 May-Jun;12(3):384-418. [PubMed] [Google Scholar]

12. Rouse MJ.Continuing professional development in pharmacy. Am J Heal Pharm. 2004;61:2069-76. [Google Scholar]

13. Barry AR, Pammett RT. Applying the guidelines for pharmacists integrating into primary care teams. Can Pharm J. 2016 Jul;149(4):219-25. [PubMed] [Google Scholar]

14. Dolovich L, Pottie K, Farrell B, Kaczorowski J, Sellors $C$, Gaebel K, Austin Z. The integrating family medicine and pharmacy to advance primary care therapeutics (IMPACT). ClinPharm J. 2004;137(1):22. [Google Scholar]

15. Lau HS, Florax Ch, Porsius AJ,DeBoer A. The completeness of medication histories in hospital medical records of patients admitted to general internal medicine wards. Br J Pharmacol. 2000 Jun;49(6):597-603. [PubMed] [Google Scholar]

16. Kjeldsen LJ, Olesen C, Hansen MK, Nielsen TR. Clinical outcomes used in clinical pharmacy intervention studies in secondary care. Pharmacy (Basel). 2017 May;5(2):28. [PubMed] [Google Scholar]

17. Ufitinema $Y$, Wong $R$, Adomako $E$, Kanyamarere $L$, Ntagungira EK, Kagwiza J. Increasing patient medical record completion by assigning nurses to specific patients in maternity ward at Munini hospital.On the Horizon. 2000;24(4):327-34. [Google Scholar]

18. Tola K, Abebe H, Gebremariam Y, Jikamo B. Improving completeness of inpatient medical records in Menelik II Referral Hospital, Addis Ababa, Ethiopia. Adv Public Heal. 2017:1-5. [Google Scholar]

19. Lazzerini M, Tamburlini G. Hospital care for children : quality assessment and improvement tool. World Heal Organ. 2015;9(3):1.

20. Najim HD, Abdulridha MK, Abbas KM. Retrospective assessment of clinical pharmacist medication sheets documentation completeness from a sample of Iraqi health care units. 2020;20(2):228-41. [Google Scholar]

21. Khdour MR, Jarab AS, Adas HO, Samaro EZ, Mukattash $\mathrm{TL}$, Hallak HO. Identification of drug-related problems: a prospective study in two general hospitals. Curr Clin Pharmacol. 2012 Nov;7(4):276-81. [PubMed] [Google Scholar]

22. ViktilKK, Blix HS, Moger TA, Reikvam A. Polypharmacy as commonly defined is an indicator of limited value 
in the assessment of drug related problems. Br J Clin Pharmacol.2007 Feb;63(2):187-95. [PubMed] [Google Scholar]

23. Silva C, Ramalho C, Luz I, Monteiro J, Fresco P. Drugrelated problems in institutionalized, polymedicated elderly patients: opportunities for pharmacist intervention. Int J Clin Pharm.2015 Apr;37(2):327-34. [PubMed] [Google Scholar]

24. Lenssen R, Heidenreich A, Schulz JB,Fitzner T, Trautwein $C$, Jaehde $U$, Eisert A. Analysis of drug-related problems in three departments of a German University hospital. Int J Clin Pharm2015Feb;38(1):119-26. [PubMed] [Google Scholar]

25. Tully MP, Buchan IE. Prescribing errors during hospital inpatient care: factors influencing identification by pharmacists. Pharm World Sci 2009 Dec;31(6):682-8. [PubMed] [Google Scholar]

26. Mshiemish BA. Role of the clinical pharmacist in reducing preventable adverse drug events. Iraqi J Pharm Sci. 2011 Sep;20(2):85-90. [Google Scholar]

27. Bose NM, Mathew M, Joy B, Joel JJ, Rajesh KS, Raj $\mathrm{KCB}$, Nandakumar UP. Assessment of drug related problems in the general medicine ward of a multispeciality teaching hospital. Int J Pharm Res. 2019Jul;11(3):52-60.

28. Yismaw MB, Adam $\mathrm{H}$, Engidawork E. Identification and resolution of drug-related problems among childhood cancer patients in Ethiopia. J Oncol. 2020 Mar;2020:6785835. [PubMed] [Google Scholar]

29. Hohmann C, Eickhof C, Klotz JM, Schulz M, Radziwill R. Development of a classifcation system for drugrelated problems in the hospital setting (APS-Doc) and assessment of the inter-rater reliability.J Clin Pharm Ther. 2012 Jun;37(3):276-81. [PubMed] [Google Scholar]

30. Taeqtmeyer AB, Kullak-Ublick GA, Widmer N, Falk V, Jetter $A$. Clinical usefulness of electronic drug-drug interaction checking in the care of cardiovascular surgery inpatients. Cardiology. 2012;123(4):219-22. [PubMed] [Google Scholar]

31. Mohammed S, Poudel S, Laloo F, Madhur A, Robert R, Mathew $B$. Assessment of drug-related problems in a tertiary care teaching hospital, India. Asian J Pharm Clin Res. 2017;10(2):310-3.

32. Tefera GM, Zeleke AZ, Jima YM, Kebede TM. Drug therapy problems and the role of clinical pharmacist in surgery ward: prospective observational and interventional study. Drug Healthc Patient Saf. 2020 May;12:71-83. [PubMed] [Google Scholar]

33. Saldanha V, Randall Martins R, Lima SIVC, Batista De Araujo I, Gouveia Oliveira A. Incidence, types and acceptability of pharmaceutical interventions about drug related problems in a general hospital: an open prospective cohort. BMJ Open. 2020 Apr;10(4):1-8. [PubMed] [Google Scholar]

34. Meng L, Qu C, Qin X, Huang H, Hu Y, Qiu F, Sun S. Drug-related problems among hospitalized surgical elderly patients in China. Biomed Res Int. 2021 Feb;2021:8830606. [PubMed] [Google Scholar]

35. Smedberg J, Brathen M, Waka MS, Jacobsen AF, Gjerdalen G, Nordeng H. Medication use and drugrelated problems among women at maternity wards-a cross-sectional study from two Norwegian hospitals. Eur J Clin Pharmacol. 2016 Jul;72(7):849-57. [PubMed] [Google Scholar]

36. Thompson R, Whennan L, Liang J, Alderman C,Grzeskowiak LE. Investigating the frequency and nature of medication-related problems in the Women's health unit of an Australian tertiary teaching hospital. Ann Pharmacother. 2015 Jul;49(7):770-6. [PubMed] [Google Scholar]

37. Ahmed SM, Sundby J,Aragaw YA, Nordeng $H$. Medication-related problems among hospitalized pregnant women in a tertiary teaching hospital in Ethiopia: a prospective observational study. BMC Pregnancy Childbirth. 2007 Nov;20(1):737. [PubMed] [Google Scholar]

38. Ku LC, Smith PB. Dosing in neonates: special considerations in physiology and trial design. Pediatr Res. 2015 Jan;77(1-1):2-9. [PubMed] [Google Scholar]

39. Rashed AN, Neubert A, Tomlin S, Jackman J, Alhamdan $\mathrm{H}$, AlShaikh A, Attar A, Aseeri M, Wilton L, Wong IC. Epidemiology and potential associated risk factors of drug-related problems in hospitalised children in the United Kingdom and Saudi Arabia. Eur J Clin Pharmacol.2012 Dec;68(12):1657-66. [PubMed] [Google Scholar]

40. Jose B, Shareef J, Shenoy R. Assessment of drug related problems and pharmacist intervention in pediatric drug therapy in a tertiary care teaching hospital. Am J Pharm Tech Res. 2016;6(2):209-18.

41. Bedouch $P$, Charpiat B, Conort O, Rose FX, Escofier L, Juste $M$, Roubille R, Allenet. Assessment of clinical pharmacists' interventions in French hospitals: results of a multicenter study. Ann Pharmacother. 2008 Jul;42(7-8):1095-103. [PubMed] [Google Scholar]

42. Birand N, Boşnak AS, Diker Ö, Abdikarim A, Başgut $B$. The role of the pharmacist in the multidisciplinary approach to the prevention and resolution of drugrelated problems in cancer chemotherapy. J Oncol Pharm Pract. 2019 Sep;25(6):1312-20. [PubMed] [Google Scholar]

43. Cehajic I, Bergan S, Bjordal K. Pharmacist assessment of drug-related problems on an oncology ward. Eur J Hosp Pharm. 2015;22(4):194-7. [Google Scholar]

44. Basger BJ, Moles JR, Chen TF. Application of drug-related 
problem (DRP) classification systems: a review of the literature. Eur J Clin Pharmacol. 2014 Jul;70(7):799-815. [PubMed] [Google Scholar]

45. Ahjel SW, Al-Jumaili AA. The pharmacist's missing role in the COVID-19 pandemic. Innov Pharm.2020 Apr;11(2):1-2. [PubMed] [Google Scholar]

46. Visacri MB, Figueiredo IV, Lima TM. Role of pharmacist during the COVID-19 pandemic: a scoping review. Res Social Adm Pharm. 2021 Jan;17(1):1799-806. [PubMed] [Google Scholar]

47. Bedouch P, Tessier A, Baudrant M, Labarere J, Foroni L, Calop J, Bosson JL, Allenet B. Computerized physician order entry system combined with on-ward pharmacist: analysis of pharmacists' interventions. J Eval Clin Pract. 2012 Aug;18(4):911-8. [PubMed] [Google Scholar]

48. Falcão F, Viegas E, Lopes $C$, Branco R, Parrinha A, Alves ML, Leal F, Pina V, Madureira B, Cavaco P, Santos S, Carreira. Hospital pharmacist interventions in a central hospital. Eur J Hosp Pharm. 2015;22(2):94-7. [Google Scholar]

49. Zillich AJ, McDonough RP, Carter BL, Doucette WR. Influential characteristics of physician/pharmacist collaborative relationships. Ann Pharmacother. 2004 May;38(5):764-70. [PubMed] [Google Scholar] 